\title{
Membrane Permeability Threshold for Osmotic Power Plant Efficiency
}

\author{
* A. Berger'1, A. Lebrun², S. Khan ${ }^{3}$, Q. Masson-Pilet ${ }^{4}$, A. Supizet ${ }^{5}$ \\ 1, 2, 3, 4, 5 ECE Paris School of Engineering, France \\ IE mail: quentin.masson-pilet@edu.ece.fr
}

\begin{tabular}{l}
\hline A R T I C L E I N F O: \\
\hline Article history: \\
Received 2 August 2017 \\
Accepted 23 August 2017 \\
Available online 12 October \\
2017 \\
\hline Keywords: \\
Osmotic Energy, \\
Membranes, \\
Permeability, \\
Osmotic Pressure. \\
\hline This work is licensed under a \\
Creative Commons Attribution \\
\hline NonCommercial - NoDerivs 4.0. \\
\hline "CC-BY-NC-ND" \\
\hline
\end{tabular}

\begin{abstract}
A B S T R A C T
In a context of ever-growing electricity consumption and need for less polluting sources of energy, salinity gradient power (SGP) based on osmosis is a promising technology. Salinity difference between two solutions separated by a semi-permeable membrane leads to the pressure increase. The aim of this study is to find the critical permeability threshold of a membrane for the dimensioning an osmotic power plant. Using Spiegler-Kedem equations, the various fluxes across the membrane have been calculated, and delivered power is explicitly derived in terms of system parameters. A necessary condition for economic viability is that its upper bound is larger than a critical threshold value below which osmotic power plant is not profitable. As it is directly proportional to membrane permeability, fixing the optimal membrane permeability value will in turn enable conceive more efficient membranes specifically made for osmotic energy production, as such membranes do not exist today. JOURNAL OF CONTEMPORARY URBAN AFFAIRS (2017) 1(3), 49-53. https://doi.org/10.25034/ijcua.2018.3679
\end{abstract}

Www.ijcua.com

Copyright (C) 2017 Journal Of Contemporary Urban Affairs. All rights reserved.

\section{Introduction}

The considerable and very fast growing energy consumption consecutive to the economic development of many countries is acutely raising the question of avoiding disastrous environmental consequences which could inevitably occur if only conventional fossil sources are used. To cope with such situation, a large effort has been oriented toward other sources such as less damaging renewable ones (Lewis, et al., 2011; Kumar, et al., 2011). Aside solar, wind, geothermal and hydraulic sources, they also include other less evident ones which may however represent interesting alternatives in specific situations.

Such is the osmotic power which is the process of converting the pressure differential between water with high salinity and water with lower or no salinity into hydraulic pressure (Loeb, 1975;
Mishra, 2013; Kho, 2010; The European Commission, 2004; Helfer, et al., 2013; Skilhagen, et al., 2012; Skilhagen, and Aaberg, 2012). The harnessing of this energy for conversion into power can be accomplished by means of Pressure Retarded Osmosis (PRO) (Kim, and Elimelech, 2013; Helfer, et al., 2014; Wang, et al., 2012). This technique uses a semipermeable membrane to separate a less concentrated solution, or solvent, (for example, fresh water) from a more concentrated and pressurized solution (for example sea water), allowing the solvent to pass to the concentrated solution side (Post, 2009). The additional volume increases the pressure on this side, which can be depressurized by a hydro-turbine to produce power and

*Corresponding Author:

ECE Paris School of Engineering, France

E-mail address: quentin.masson-pilet@edu.ece.fr 
electricity (Kleiterp, 2012) .As seventy percent of Earth surface is covered with water, 97 percent of which is saltwater, the process created by mixing seawater with freshwater generates a resulting osmotic power which could serve as both renewable and consistent electricity source. While still in early stages, best estimates of the global production potential of osmotic power exceed 1,600 terawatt-hours, the equivalent of half of Europe entire energy demand. There are two primary sources for osmotic power: 1) natural occurrence where river water meets the sea water, and 2) merging two man-made water sources from processing plants

Both methods can be viable but in 1), seawater averages 40 grams of salt/ liter + River Water, less power is provided than in than 2), where brine (from desalination) averages 60 grams of salt/ liter + treated water. The higher the salinity, the more free energy can be extracted, and the more power can be generated. Today osmotic power is a promising renewable energy source (RES) provided conversion factor from pressure differential can be made large enough (Dinger, et al., 2012; Braein, et al., 2010; Straub, et al., 2016). In the following, some elements on this question will be discussed in PRO case. In particular, the threshold value for permeability coefficient which characterizes membrane efficiency for viable economic application is determined.

\section{Osmosis Pressure Representation}

Potential osmotic pressure $\pi$, the maximum osmotic pressure in a solution separated from osmosed fluid by a selectively permeable membrane, is given by

$\pi=\mathrm{CiRT}$

with $\pi$ the potential osmotic pressure $(\mathrm{Pa}), \mathrm{C}$ the solute molar concentration $\left(\mathrm{mol} \mathrm{m}{ }^{-3}\right), \mathrm{R}=8,314 \mathrm{~J} \cdot \mathrm{mol}^{-1} \cdot \mathrm{K}^{-1}$, T solution temperature $\left({ }^{\circ} \mathrm{K}\right)$, and I the particle number per entity. Given the solutions, D and $\mathrm{F}$ with respective osmotic pressures $\pi_{\mathrm{D}}$ and $\pi_{\mathrm{F}}$, where $\mathrm{D}$ is draw solution (most concentrated), and $\mathrm{F}$ feed one (less concentrated), osmotic pressure difference $\Delta \pi=\pi_{\mathrm{D}}-\pi_{\mathrm{F}}$ between the two solutions is typically equal to 12 bars for water fluid, ie, $12.10^{5} \mathrm{~Pa}$. Let $\Delta \mathrm{P}=\mathrm{P}_{\mathrm{D}}-\mathrm{P}_{\mathrm{F}}$ with $\mathrm{P}_{\mathrm{D}}$ and $\mathrm{P}_{\mathrm{F}}$ the pressures of solutions D and F. With Spiegler-Kedem [18] model flux equations can be integrated and one gets volume and solute fluxes $J_{v}$ and $J_{s}$ flowing through the membrane with pressure retarded osmosis

$$
\mathrm{J}_{\mathrm{v}}=\mathrm{A}(\sigma \Delta \pi-\Delta \mathrm{P}) \quad ; \quad \mathrm{J}_{\mathrm{s}}=-\left(1-\mathrm{E}_{\mathrm{m}}\right)^{-1}\left(\mathrm{~J}_{\mathrm{v}} \mathrm{C}_{\mathrm{d}} \mathrm{E}_{\mathrm{m}}-\mathrm{C}_{\mathrm{i}}\right)(2)
$$

with $\mathrm{J}_{\mathrm{v}}, \mathrm{J}_{\mathrm{s}}\left(\mathrm{m} . \mathrm{s}^{\mathbf{1}}\right)$ the volume and solute fluxes across the membrane, $\sigma$ the solute reflection coefficient, $\mathrm{A}\left(\mathrm{m} . \mathrm{Pa}^{-1}\right.$ $\left.\mathrm{s}^{-\mathbf{1}}\right)$ the membrane fluid permeability, and $\mathrm{E}_{\mathrm{m}}=\exp -[(1$ $\left.-\sigma) J_{v} L \omega^{-1}\right]$ with $\omega$ the solute permeability. Similarly in the support one gets $J_{s}=-\left(1-E_{s}\right)^{-1}\left(J_{v} C_{i} E_{s}-C_{f}\right)(3)$

with $C_{d}, C_{i}$ and $C_{f}$ the solute concentration in the draw solution, at the barrier-layer/support interface, and in the feed solution respectively, and $\mathrm{E}_{\mathrm{s}}=\exp -\left[\mathrm{J}_{\mathrm{v}} \delta \mathrm{D}_{\mathrm{e}}{ }^{-1}\right]$ with $\delta$ the support thickness. Equality of fluxes in the barrier layer and the support gives from $(1,2,3)$ the non-dimensional equation

$\alpha\left\{(1-\sigma)\left(1-E^{1-\sigma}\right)^{-1}+E^{\rho}\left(1-E^{\rho}\right)^{-1}\right\}=(1-r)\left(1-E^{\rho}\right)^{-1}-\sigma$

with $\alpha=1-\mathrm{C}_{\mathrm{i}} / \mathrm{C}_{\mathrm{d}}, \sigma$ the solute reflection coefficient, $\mathrm{r}=$ $\mathrm{C}_{\mathrm{f}} / \mathrm{C}_{\mathrm{d}}, \rho=\delta \omega / \mathrm{D}_{\mathrm{e}} \mathrm{L}, \delta$ the support thickness, $\mathrm{L}$ the barrier layer thickness, $\mathrm{D}_{\mathrm{e}}$ the effective diffusion coefficient of the solute, $\mathrm{E}=\exp -\mathrm{X}, \mathrm{X}=\mathrm{F}(\sigma \alpha-\langle\Delta \mathrm{P}\rangle), \mathrm{F}=\mathrm{ART} \nu \mathrm{C}_{\mathrm{d}} \mathrm{L} / \omega, v$ the salt stoichiometric coefficient and finally $\langle\Delta \mathrm{P}\rangle=\left(\mathrm{P}_{\mathrm{d}}\right.$ - $\left.\mathrm{P}_{\mathrm{f}}\right) / \mathrm{RT} v \mathrm{C}_{\mathrm{d}}$. For a given dimensionless hydrostaticpressure difference $\langle\Delta \mathrm{P}\rangle$, (4) is a transcendental equation in $\alpha$ (dimensionless concentration difference across the barrier layer) which determines the operating conditions of the osmotic plant for a given set of system parameters.

\section{Osmotic Power Plant Production}

The basic energy production system is composed of a compression unit which delivers pressurized salted water injected in a chamber with a filtering membrane across which a flux of salted water $J_{s}$ is crossing, see Figure 1.

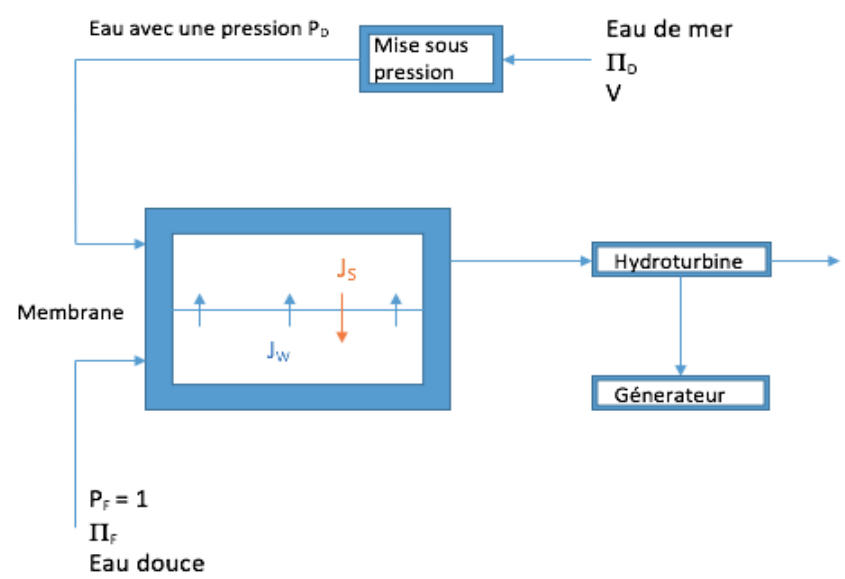

Figure 1. Sketch of Osmotic Plant Balance $J_{s}$ is Salt Flux across the Membrane.

The power produced per surface unit of installed membrane is given $\mathrm{W}=\mathrm{J}_{\mathrm{m}} \Delta \mathrm{P}$ with $\mathrm{W}$ in Watts $/ \mathrm{m}^{-2}$, or else in non-dimensional form

$\langle\mathrm{W}\rangle=\mathrm{W} / \mathrm{A}\left(\mathrm{RT} v \mathrm{C}_{\mathrm{d}}\right)^{2}=\langle\Delta \mathrm{P}\rangle(\sigma \alpha-\langle\Delta \mathrm{P}\rangle)$ 
$\langle\mathrm{W}\rangle$ is maximum when $\langle\Delta \mathrm{P}\rangle=\sigma \alpha / 2$ and is then equal to $\langle\mathrm{W}\rangle=(\sigma \alpha)^{2} / 4$. But this is not necessarily possible as $\alpha$ and $\langle\Delta \mathrm{P}\rangle$ are also linked by (4) which imposes a constraint on system coefficients. One effectively gets for $\mathrm{z}=\sigma \alpha$ the transcendental equation

$$
\mathrm{z}\left\{(1-\sigma)\left(1-\mathrm{E}(\mathrm{z})^{1-\sigma}\right)^{-1}+\mathrm{E}(\mathrm{z})^{\rho}\left(1-\mathrm{E}(\mathrm{z})^{\rho}\right)^{-1}\right\}=\sigma(1-\mathrm{r})\left(1-\mathrm{E}(\mathrm{z})^{\rho}\right)^{-1}-\sigma^{2}
$$

with $\mathrm{E}(\mathrm{z})=\exp -.5 \mathrm{Fz}$ which relates "physical" $\mathrm{z}$ (concentration performance) to "technical" $F$ (barrier quality). From this different limits can be evaluated for possible power output from the system (Yip, and Elimelech, 2012; Yip, and Elimelech, 2011; Lin et al., 2014). However simple ones are directly obtained from (6) for $\langle W\rangle$. In the case of very large $\rho$ for instance, (4) takes the very simple form

$$
\mathrm{Y}=-(\operatorname{Ln}(1-\mathrm{x})) / \mathrm{x}
$$

where $\mathrm{x}=\alpha\left[1-\mathrm{r}\left((1-\sigma)^{-1}\right]\right.$ and $\mathrm{Y}=\sigma(1-\sigma-\mathrm{r}) \mathrm{F} / 2$. In definition interval $\mathrm{x} \in[0,1], \mathrm{Y}$ is monotonically increasing from 1 to $+\infty$, and normalized delivered power $\langle\mathrm{W}\rangle=\mathrm{Kx}^{2}$, with $\mathrm{K}=\sigma^{2} / 4\left[1-\mathrm{r}\left((1-\sigma)^{-1}\right]^{2}\right.$, varies monotonically between 0 and $\mathrm{K}$, showing that larger $\langle\mathrm{W}\rangle$ corresponds to larger $\mathrm{x}$. More generally parametric dependence of power output $\mathrm{W}$ can be obtained from (6) to get best parameter range. When returning to dimensional expression, $\mathrm{W}$ is upper bounded by $\mathrm{W}_{\text {sup }}=\mathrm{KA}\left(\mathrm{RTv} \mathrm{C}_{\mathrm{d}}\right)^{2}$, and a necessary condition for economic efficiency is that

$\mathrm{W}_{\text {sup }}=\mathrm{KA}\left(\mathrm{RTv} \mathrm{C}_{\mathrm{d}}\right)^{2} \geq \mathrm{W}_{\text {crit }}$

where $\mathrm{W}_{\text {crit }}$ is the threshold value above which the osmotic plant is viable. $\mathrm{W}_{\text {sup }}$ is larger with larger draw concentration $\mathrm{C}_{\mathrm{d}}$, larger temperature $\mathrm{T}$ and larger $\mathrm{A}$, which has to be determined to satisfy economic system efficiency demand, ie here $\mathrm{A} \geq \mathrm{A}_{\text {crit }}=$ $4 \mathrm{~W}_{\text {crit }} \Delta \pi^{2}$. For usual figure of delivered power $\mathrm{W}_{\mathrm{d}}=$ $5 \mathrm{Wm}^{-2}$, and with typical $\Delta \pi=12.10^{5} \mathrm{~Pa}$ for water, one gets, for instance, $\mathrm{A} \geq \mathrm{A}_{\text {crit }}=1.38 \mathrm{mPa}^{-1} \mathrm{~s}^{-1}$. More generally the variation of $\mathrm{A}_{\text {crit }}$ vs $\Delta \pi$, sees Figure 2, indicates for $\Delta \pi \in\left[6.10^{5}, 20.10^{5}\right]$ the "efficiency" interval $\mathrm{A} \in\left[4.910^{-12}, 5.410^{-11}\right]$ which is still at technical limit today (Straub, et al., 2016; Zhang, and Chung, 2013). To cope with these economic operating constraints, extension of simple osmotic barrier effect have been recently considered (Chou, et al., 2013; Chou, et al., 2012; Yip, et al, 2010; Banchik, et al., 2014; Mc Cutcheon, and Elimelech, 2007; Cath, et al., 2013; Chen, et al., 2016; She', et al., 2016; Chou, et al., 2013; Hickenbottom, et al., 2016; Dechadilok, and Deen, 2006).
A coupled system with solar plant will be discussed elsewhere.

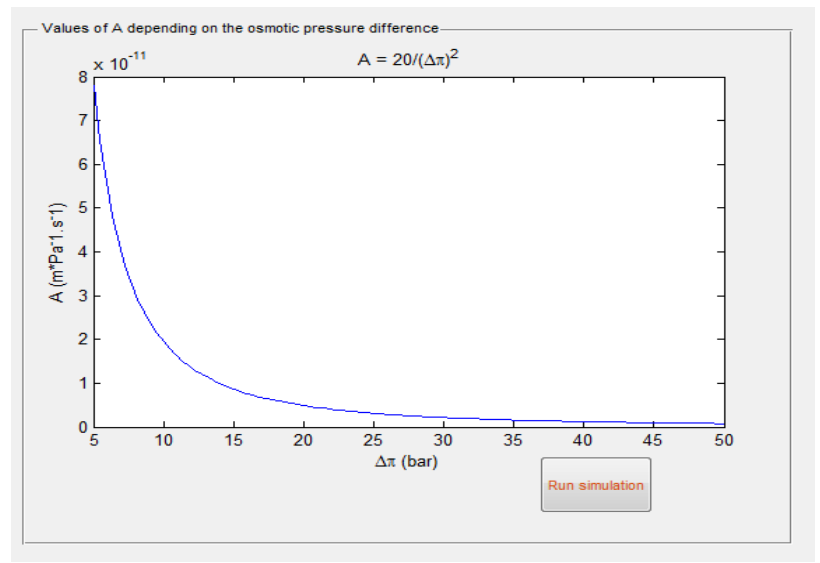

Figure 2 . Permeability Coefficient vs Osmotic Pressure Difference.

\section{Conclusion}

From analysis of equations representing osmotic physical phenomenon, it is shown that in Pressure Retarded Osmosis case, the harnessing of salinity-gradient energy taking place at the interface between waters of different salt concentration could provide an interesting and almost inexhaustible energy source if systems coefficients satisfy operating conditions which have been explicitly stated within SpieglerKedem model. However, even in optimum mode operating case, satisfaction of economic viability condition expressed by fixed specific membrane power output $W_{\text {thres }} \cong 5 \mathrm{Wm}^{\square 2}$ is not always met. Aside theoretical research on optimizing system operating mode, this weakness is urging further study of membrane physical properties, such as porosity and tortuosity pore length, to design most efficient hydraulic permeability of the barrier layer.

\section{Acknowledgments}

The authors are very much indebted to ECE Paris School of Engineering for having provided the necessary setup for the development of the project, to Drs. S. Mouhali for advices during the research and Pr. M. Cotsaftis for help in the preparation of the manuscript.

\section{References}

Banchik, L.D., Sharqawy, M.H., Lienhard, J.H. (2014). Limits of Power Production due to Finite Membrane Area in Pressure Retarded Osmosis, J. Membr. Sci., 468, 81-89.

Braein, S., Sandvik, $\varnothing$.S., Skilhagen, S.E. (2010) .Osmotic Power: from Prototype to Industry- 
What Will it Take?, Proc. 3rd Intern. Conf. on Ocean Energy, ICOE, Bilbao: Spain.

Cath, T. Y., Elimelech, M., McCutcheon, J. R., Mcginnis, R. L., Achilli, A., Anastasio, D., Brady, A. R., Childress, A. E., Farr, I. V., Hancock, N. T., Lampi, J., Nghiem, L. D., Xie, M. \& Yip, N. Yin. (2013). Standard methodology for evaluating membrane performance in osmotically driven membrane processes. Desalination, 312 (N/A), 31-38.

Chen, Y., Setiawan, L., Chou, S., Hu, X., Wang, R. (2016). Identification of Safe and Stable Operation Conditions for Pressure Retarded Osmosis with High-Performance Hollow Fiber Membrane, J. Memb. Sci., 503, pp.90-100.

Chou, S., Wang, R., Fane, A.G. (2013). Robust and High-Performance Hollow Fiber Membranes for Energy Harvesting from Salinity Gradients by Pressure Retarded Osmosis. J. Memb. Sci., 448, 44-54.

Chou, S., Wang, R., Shi, L., She, Q., Tang, C., Fane, A.G. (2012) .Thin-film Composite Hollow Fiber Membranes for Pressure Retarded Osmosis (PRO) Process with High Power Density, J Membrane Sci, 389, 25-33.

Dechadilok, P., Deen, W.M. (2006). Hindrance Factors for Diffusion and Convection in Pores, Ind. Eng. Chem. Res., 45, 6953-6959.

Dinger, F., Troendle, T., Platt, U. (2012) . Osmotic Power Plants, 3rd Osmosis Membrane Summit, Statkraft, Barcelona: Spain

Helfer, F., Sahin, O., Lemckert, C., Anissimov, Y. (2013). Salinity Gradient Energy: a New Source of Renewable Energy for Australia. Proc. Intern. Conf. of the European Water Resources Association (EWRA), Porto: Portugal.

Helfer, F., Lemckert, C., Anissimov, Y.G. (2014) . Osmotic Power with Pressure Retarded Osmosis: Theory, Performance, and Trends, J. Membranes Science, 453, 337-358.

Hickenbottom, K.L., Vanneste, J., Elimelech, M.A., Cath, T.Y. (2016). Assessing the Current State of Commercially Available Membranes and Spacers for Energy Production with Pressure Retarded Osmosis, Desalination, 389, 108-118.

Kho, J. (2010) .Osmotic Power: A Primer. San Francisco, USA: Kachan \& Co.

Kim, Y.C., Elimelech, M. (2013). Potential of Osmotic Power Generation by Pressure Retarded Osmosis Using Seawater as Feed Solution: Analysis and Experiments, J Membrane Sci, 429, 330-337

Kleiterp, R. (2012). The Feasibility of a Commercial Osmotic Power Plant, Master
Thesis, Dept of Hydraulic Engineering, Delft University of Technology, Delft:Netherlands.

Kumar, A., Schei, T., Ahenkorah, A., Rodriguez, R.C., Devernay, J.M., Freitas, M., Hall, D., Killingtveit, Å., Liu, Z. (2011). Hydropower, in: Edenhofer, O., Pichs-Madruga, R., Sokona, Y., Seyboth, K., Matschoss, P., Kadner, S., Zwickel, T., Eickemeier, P., Hansen, G., Schlömer, S., Stechow C. (Eds.). IPCC Special Report on Renewable Energy Sources and Climate Change Mitigation. Cambridge and New York, UK \&USA: Cambridge Univ. Press.

Lewis, A., Estefen, S., Huckerby, J., Musial, W., Pontes, T., Torres-Martinez, J. (2011). Ocean Energy, in: Edenhofer, O., Pichs-Madruga, R., Sokona, Y., Seyboth, K., Matschoss, P., Kadner, S., Zwickel, T., Eickemeier, P., Hansen, G., Schlömer, S., Stechow C. (Eds.). IPCC Special Report on Renewable Energy Sources and Climate Change Mitigation. Cambridge and New York, UK \& USA: Cambridge Univ. Press.

Lin, S.H., Straub, A.P., Elimelech, M. (2014). Thermodynamic Limits of Extractable Energy by Pressure Retarded Osmosis, Energy Environ. Sci., 7, pp.2706-2714.

Loeb, S. (1975). Osmotic Power Plants, Science, $189,654-655$.

Mc Cutcheon, J.R., Elimelech, M.A. (2007) . Modeling Water Flux in Forward Osmosis: Implications for Improved Membrane Design, AIChE J., 53, 1736-1744.

Mishra A. (2013). Osmotic Power-Huge Source of Renewable Energy, Int J Sci Eng Res, 4, 1-6.

Post, J.W. (2009) . Blue Energy: Electricity Production from Salinity Gradients by Reverse Electro-dialysis, PhD thesis, Sub-dept of Environmental Technology, Wageningen University, Wageningen: Netherlands.

She, Q., Wei. J., Ma. N., Sim, V., Fane, A. Rong, G., Wang, R., Tang, C.Y. (2016). Fabrication and Characterization of Fabric-reinforced Pressure Retarded Osmosis Membranes for Osmotic Power Harvesting, J. Memb. Sci., 504, 75-88.

Skilhagen, S.E., Dugstad, J.E., Aaberg R.J. (2012). Osmotic Power - Power Production Based on the Osmotic Pressure Difference between Waters with Varying Salt Gradients, Desalination, 220, 476-482.

Skilhagen, S.E., Aaberg R.J. (2006) . Power Production Based on the Osmotic Pressure Difference between Fresh Water and Sea Water, European Seminar on Offshore Wind and Other Marine Renewable Energies in 
Mediterranean and European Seas (Owemes), Owemes, Citavecchia: Italy.

Straub, A.P., Deshmukh, A., Elimelech, M. (2016). Pressure-retarded Osmosis for Power Generation from Salinity Gradients: is it Viable? Energy Environ. Sci., 9, 31-48.

Spiegler, K.S., Kedem, O. (1966): Thermodynamics of Hyper-filtration (Reverse Osmosis): Criteria for Efficient Membranes, Desalination, And 1,31 1-326.

The Salinity Project Group, The Salinity Power Project: Power Production from the Osmotic Pressure Difference between Fresh Water and Sea Water - Final Report, (2004). The European Commission, Bruxelles, Lisbon.

Wang, R., Tang, C., Fane, A.G. (2012). Development of Pressure Retarded Osmosis (PRO) Membranes with High Power Density for Osmotic Power Harvesting, in: 3rd Osmosis Membrane Summit, Statkraft, and Barcelona: Spain.
Yip, N.Y., Tiraferri, A., Phillip, W.A., Schiffman, J.D., Elimelech, M. (2010) . High-Performance Thinfilm Composite forward Osmosis Membranes, Environ Sci Technol, 44, 3812-3818.

Yip, N.Y., Elimelech, M. (2012). Thermodynamic and Energy Efficiency Analysis of Power Generation from Natural Salinity Gradients by Pressure Retarded Osmosis, Environ. Sci. Technol., 46, 5230-5239.

Yip, N.Y., Elimelech, M. (2011). Performance Limiting Effects in Power Generation from Salinity Gradients by Pressure Retarded Osmosis, Environ Sci Technol, 45, 10273-10282.

Zhang, S., Chung, T.S. (2013). Minimizing the Instant and Accumulative Effects of Salt Permeability to Sustain Ultrahigh Osmotic Power Density, Environ. Sci. Technol., 47, 10085-10092. 